William H. Noble MD FRCP,* Jacques St-Amand MD FRCP $†$

\title{
Amniotic fluid embolus
}

A case report of a 27-yr-old healthy patient for Caesarean section under epidural anaesthesia is presented. The patient suffered an acute cardiorespiratory collapse when the infant's head was being delivered through the anterior abdominal wall. The patient remained cyanosed after proper tracheal intubation and pulmonary ventilation with $100 \% \mathrm{O}_{2}$. Hypotension was difficult to treat but returned to normal $25 \mathrm{~min}$ after the event. A pulmonary artery catheter inserted three hours afier the event showed normal pressures and a high cardiac output. The patient suffered permanent neurological damage. The differential diagnosis is discussed and current concepts of the aetiology and management of amniotic fluid embolism reviewed.

Il s'agit du cas d'une patiente bien portante subissant une césarienne sous anesthésie épidurale. La patiente présente une collapsus cardiorespiratoire aigu au moment où la tête de l'enfant est dégagée à travers la paroi abdominale antérieure. La patiente reste cyanosée après une intubation trachéale (correcte) et une ventilation pulmonaire avec $100 \%$ d'O $\mathrm{O}_{2}$. Lhypotension est difficile à traiter mais revient à la normale 25 minutes plus tard. Un cathéter Swann-Ganz inséré trois heures après l'évènement donne des pressions normales et un débit cardiaque élevé. La patiente a subi une atteinte neurologique définitive. Le diagnostic différentiel est discuté et les concepts habituels de l'étiologie et du traitement de l'embolie amniotique sont revus.

\section{Case report}

In 1987, a 27-yr-old healthy woman presented for an elective Caesarean section. She had had a previous Caesarean section under general anaesthesia without difficulty. There were no problems found on history or physical examination. The patient decided after discussion with her general practitioner and anaesthetist to have an epidural an-

\section{Key words}

ANAESTHESIA: obstetric; EMBOLISM: amniotic fluid.

From *St. Michael's Hospital and University of Toronto, and †Greater Niagara General Hospital.

Address correspondence to: Dr. William H. Noble,

Department of Anaesthesia, St. Michael's Hospital, 30 Bond

St., Toronto, Ontario., M5B 1W8.

Accepted for publication 25th June, 1993. aesthetic for pain control. Haemoglobin and urinalysis were normal. She was given $30 \mathrm{ml} \mathrm{Na}$ citrate outside the OR.

At 08:00 a continuous epidural catheter was inserted with the patient in the seated position with no difficulty. The patient was positioned with a wedge under her right hip. Intermittent injections to a total of $22 \mathrm{ml}$ lidocaine $2 \%$ with epinephrine were placed in the epidural space. One litre of normal saline was given $i v$. The monitors were a hard copy blood pressure (BP) showing normal fluctuating BP and pulse and an ECG. The epidural level was tested and found to be at the $T_{5-6}$ level. Surgery started 20 min after the epidural was inserted. The patient was carrying on a normal social conversation.

At 08:45 (as the head of a normal crying infant was delivered through the anterior abdominal wall) the mother suddenly complained of shortness of breath (SOB), began to hyperventilate, coughed and became cyanosed. The blood pressure decreased, the sinus heart rate increased, and she may have suffered a seizure (there was thrashing of both arms). Almost immediately BP and pulse on the Dinemapp recorder were undetectable (Table I - 8:48) but the ECG showed sinus tachycardia. The airway was managed initially with mask and oxygen and then the trachea was intubated without difficulty. Breathing was managed initially with mask ventilation with oxygen and continued with bag ventilation through the endotracheal tube. There was no bronchospasm and air entry was equal bilaterally.

Circulation was managed by the infusion of fluid, drugs which included ephedrine, epinephrine, $\mathrm{NaHCO}_{3}$, isuprel and atropine, and cardiac massage. Other drugs given included $\mathrm{Na}$ citrate preoperatively, succinylcholine, atracurium, thiopentone, and oxytocin. At various times another anaesthetist, two intensive care physicians and nurses were in the operating room observing and helping with the resuscitation. These manoeuvres were successful in returning blood pressure but the patient remained cyanosed in spite of an adequate blood pressure and positive pressure ventilation with $100 \% \mathrm{O}_{2}$.

The blood pressure decreased a second time (Table I - 9:01) and again the patient was resuscitated. The first inadequate blood pressure (taken from the Dinemapp) was reconded at 08:48 (only one reading at this level). The total time between adequate blood pressures was seven minutes. The total time of inadequate blood 
TABLE I Dinemapp recording

\begin{tabular}{lcc}
\hline Time & $B P$ & Heart rate \\
\hline $8: 33$ & $149 / 88$ & 74 \\
$8: 36$ & $114 / 87$ & 94 \\
$8: 41$ & $69 / 43$ & 88 \\
$8: 45$ & $76 / 49$ & 115 \\
$8: 48$ & $00 / 00$ & 0 \\
$8: 52$ & $86 / 45$ & 147 \\
$8: 54$ & $93 / 34$ & 125 \\
$8: 57$ & $49 / 33$ & 156 \\
$8: 59$ & $53 / 23$ & 0 \\
$9: 01$ & $00 / 00$ & 0 \\
$9: 03$ & $36 / 22$ & 0 \\
$9: 05$ & $00 / 00$ & 0 \\
$9: 08$ & $96 / 68$ & 153 \\
$9: 10$ & $133 / 76$ & 159 \\
$9: 12$ & $154 / 91$ & 153 \\
\hline
\end{tabular}

pressure as recorded by the Dinemapp therefore could be as short as $15 \mathrm{sec}$ (since it takes that long to make a recording) or as long as seven minutes. The second inadequate blood pressure was recorded at 09:01 (three readings at low levels) with a total time between adequate blood pressures of nine minutes. This total time of inadequate blood pressure as recorded by the Dinemapp therefore could be as short as five min or as long as nine minutes. Finally, the patient "pinked up," the operation was completed and the patient was sent to the ICU.

In the ICU there was good urine output at all times. The first blood gas analysis indicated a mild respiratory, more severe metabolic acidosis and no hypoxaemia ( $\mathrm{pH}$ 7.12, $\mathrm{PaCO}_{2} 45 \mathrm{mmHg}$, and $\mathrm{PaO}_{2} 470 \mathrm{mmHg}$ ). The chest $x$-ray was normal. Three hours later, a pulmonary artery catheter was inserted (11:30) and the results were normal except for a high cardiac output (pulmonary artery pressure (PPA) $24 / 7 \mathrm{mmHg}$, cardiac output (Q) $8.4 \mathrm{~L} \cdot \mathrm{min}^{-1}$ and pulmonary wedge pressure (Pw) $12 \mathrm{mmHg}$ ) at a time when the heart rate was $130 \mathrm{~min}^{-1}$ and blood pressure was $143 / 90 \mathrm{mmHg}$. The patient developed disseminated intravascular coagulation (DIC - fibrin degradation products (FDP) $>40 \mu \mathrm{g} \cdot \mathrm{ml}^{-1}$ (normal $<10$ ),

\section{GLOSSARY OF TERMS}

PPA - Pulmonary artery pressure $(\mathrm{mmHg})$

$\mathrm{Pw}$ - Pulmonary wedge pressure ( $\mathrm{mmHg}$ )

Pmv - Pulmonary microvascular pressure $(\mathrm{mmHg})$

$\mathrm{Pla}$ - Left atrial pressure $(\mathrm{mmHg})$

$\dot{Q}$ - Cardiac output $\left(\mathrm{L} \cdot \min ^{-1}\right)$

PT - Prothrombin time (sec)

PTT - Partial thromboplastin time (sec)

FDP - Fibrin degradation products $\left(\mu \mathrm{g} \cdot \mathrm{ml}^{-1}\right)$

AFE - Amniotic fluid embolus partial thromboplastin time (PTT) $87 \mathrm{sec}(n=<35)$, prothrombin time (PT) $17.7 \mathrm{sec}(n<14)$, Fibrinogen $1.9 \mathrm{~g} \cdot \mathrm{L}^{-1}(n>4)$, platelet count decreased from 383,000 $\times 10^{9} \cdot \mathrm{L}^{-1}$ preoperatively to $145,000 \times 10^{9} \cdot \mathrm{L}^{-1}$ postoperatively) and she bled vaginally. Blood loss was replaced and coagulation factors infused. A blood sample was not taken to identify if "squames" were present. A lung scan was ordered but once the patient stabilized and before the scan was done she was transferred to a teaching hospital where mechanical ventilation was continued.

At the teaching hospital an EEG showed diffuse changes. A CAT scan showed no definite infarct. There were ECG changes described first as consistent with anterior ischaemia and then borderline flat $\mathrm{T}$ waves in leads $V_{2}$ and $V_{3}$ (two days later). In one week the ECG was normal. The patient was left with severe diffuse neurological impairment. No new diagnoses were made.

\section{Discussion}

Several possible diagnoses were considered in this patient.

\section{(a) Anaesthesia related problems (Table II):}

Total spinal anaesthesia would have occurred immediately after the local anaesthetic was injected (Table II) and would result in immediate loss of consciousness and apnoea. Heart rate would approach that of a dennervated heart $\left(72 \cdot \min ^{-1}\right)$ and BP might decrease depending on the intravascular volume status. Positive pressure ventilation with $100 \% \mathrm{O}_{2}$ should correct the cyanosis. None of these occurred.

Intravenous bolus of local anaesthetic would create symptoms immediately after the local anaesthetic was injected and result in confusion, loss of consciousness, convulsions, possible decrease in BP and apnoea. None of these occurred at the appropriate time.

Slow absorption of local anaesthesia over time (10-30 min) from the epidural space would create hyperexcitability, confusion, convulsions, and loss of consciousness. The events would come on gradually after a dose of lidocaine of $>500 \mathrm{mg}$ (total given $440 \mathrm{mg}$ ) and is unlikely in the presence of epinephrine. This could not account for the cyanosis, the suddenness, the SOB, or massive decrease in BP. A witnessed cardiac arrest created by this mechanism would not likely result in neurological problems.

High epidural block either because too much drug has been given or because it had been placed in the subdural space (Table II) may block the muscles of breathing and 
TABLE II Effects of AFE, high epidural, subdural and total spinal

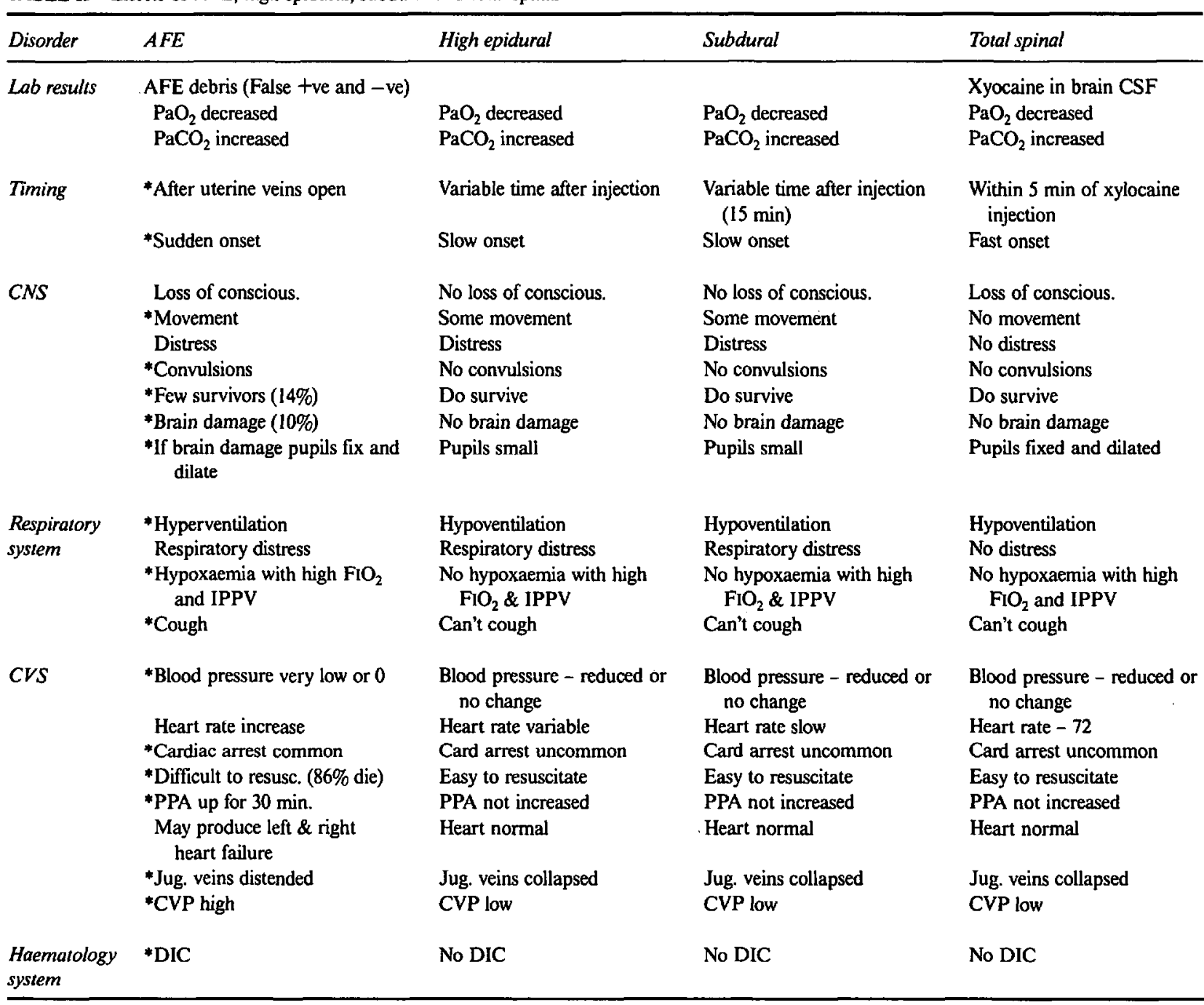

*Occurred in patient's case and different than other 3 diagnoses.

the patient will complain of gradually increasing SOB. But, the anaesthetic level was only at $\mathrm{T}_{5-6}$. This problem is usually associated with a decrease in BP that occurs slowly (over ten minutes) and that responds to fluid infusion. Fluid was infused and a slow decrease in BP did not occur. The decrease in BP should be associated with pale or white skin and not cyanosis. The patient would not be able to cough since her muscles of breathing would be too weak. Positive pressure ventilation with $100 \% \mathrm{O}_{2}$ should correct the cyanosis.

Allergic reactions to the anaesthetic drugs used in this case are extremely rare, are usually associated with bronchospasm, and if life threatening, with hypotension.

Inadequate administration of $\mathrm{O}_{2}$ Since the patient was resuscitated without changing the anaesthetic machine and $\mathrm{O}_{2}$ was administered by the anaesthetist this is ruled out.

\section{(b) Non-anaesthesia related problems}

Ruptured intracranial aneurysm was eliminated by the CAT scan.

Cerebral embolus is possible but would have been small or it would have shown up on the CAT scan. Amniotic fluid embolus to the brain may give rise to the CAT scan picture seen and be confused with global ischaemia since the emboli are small. Whether this patient had a cerebral embolus or global brain ischaemia cannot be determined but one (or both) must have occurred.

Myocardial Infarct has occurred in this type of setting 
because of the increased coagulability and heart stress of late pregnancy. Although there were ECG changes, a myocardial infarct severe enough to create cyanosis is unlikely since the chest $x$-ray was clear and the Pw normal postoperatively.

\section{Blood loss was not seen.}

Sepsis is possible but unlikely to create a sudden event and to be corrected without the use of antibiotics and DIC is likely after severe sepsis. However, cardiac arrest and cyanosis are very unlikely after sepsis and it should have responded more quickly to the infusion of fluids given and the drugs applied.

Aspiration of stomach contents could create all of the problems but the normal postoperative chest radiographs rule it out.

Pulmonary embolism: the sudden timing of the event is typical of a pulmonary embolus. The patient would complain suddenly of SOB, hyperventilate, cough, be cyanosed, and have a decrease in blood pressure and increase in heart rate, seizures proceeding to cardiac arrest that is difficult to resuscitate and might produce neurological damage in a witnessed cardiac arrest. There are several possible embolic elements (blood clot, air and amniotic fluid).

Blood clot is possible in the pregnant patient but is unlikely with the normal pulmonary vascular pressures found three hours postoperatively.

Air is possible and air emboli have been described at Caesarean section by Doppler ultrasonography. Air is entrained into the open veins in the uterus at Caesarean section and could result in all of the presenting symptoms and the late findings since the air would be rapidly absorbed from the lungs and pulmonary artery pressures postoperatively would be normal. Although DIC is possible it is unlikely.

Amniotic fluid embolus ( $A F E$ ) is the most likely diagnosis as the findings almost exactly match the expected effects of an AFE (Table II). ${ }^{8}$

\section{Amniotic fluid embolism literature review}

The primary defect created by an AFE is mechanical blockage of a part of the pulmonary arteries and vasoconstriction of the remaining vessels perhaps through the release of undefined chemicals such as prostaglandins, leukotrienes, serotonin or histamine. ${ }^{8-14}$ As a result, pulmonary artery pressure (PPA) increases. The initial rise in PPA has never been documented in patients since no patient has even had a Swan Ganz catheter in place until after the AFE occurred. ${ }^{9,10,15-22}$ (Table III) but in animals PPA returns to normal within $30 \mathrm{~min}$ of an $\mathrm{AFE}^{23-25}$ (Table IV). One patient has been described with AFE but with low pulmonary artery pressures, as in the present case, five hours after the event. ${ }^{21}$

The two major defects created by the increased PPA are a decrease in $\mathrm{O}_{2}$ transferred in the lungs and cyanosis, and a decrease in BP from the right ventricle outflow obstruction.

\section{Hypoxaemia}

The most important causes are lung and heart shunts.

\section{LUNG SHUNT}

$\dot{V} / \dot{Q}$ abnormalities: If an embolus reaches the lung it obstructs the vessels and stops perfusion to that part of the lung. Blood flow is reduced and dead space is created. This probably occurred in this case since the first $\mathrm{PaCO}_{2}$ was $45 \mathrm{mmHg}$ while the lungs were hyperventilated and which should have reduced the $\mathrm{PaCO}_{2}$ into the $20 \mathrm{mmHg}$ range. Therefore the $\mathrm{PaCO}_{2}$, although normal, supports the diagnosis of AFE. However, while it is known that hypoxaemia occurs in pulmonary embolism the reason is not agreed upon. There are several possibilities. First, areas of the lung that have not been obstructed by embolus or vasoconstriction receive too much blood flow and overwhelm the amount of ventilation to that area so that insufficient $\mathrm{O}_{2}$ is picked up by the blood going through the lung causing hypoxaemia and cyanosis. ${ }^{26}$ Second, obstruction in the pulmonary circulation (either mechanical or vasoconstrictive) results in a decrease in cardiac output that reduces the $\mathrm{O}_{2}$ content in the venous blood returning to the heart and lungs and thus magnifies the first effects. Third, emboli, or chemicals, pass through the pulmonary circulation into the coronary circulation and depress the heart leading to heart failure and pulmonary oedema. ${ }^{21}$

\section{HEART SHUNT}

The foramen does not completely close after birth in $35 \%$ of the normal population and may open with the AFE induced increase in PPA and allow blood containing AFE into the systemic circulation where it will travel to the brain. This blood that passes through the foramen has a venous $\mathrm{O}_{2}$ content so that arterial $\mathrm{O}_{2}$ concentrations decrease and this may damage the brain. Since opening of the foramen is dependent on the pressure gradient between the left and right atria any increase in PPA may be sufficient to cause this and even small numbers of emboli could create brain damage. The PPA must be 
TABLE III Human data with PPA and amniotic fluid emboli

\begin{tabular}{|c|c|c|c|c|c|c|}
\hline First author & $\begin{array}{l}\text { Time to first } \\
\text { PPA measure }\end{array}$ & $\begin{array}{l}\text { First PPA } \\
\text { (mmHg) }\end{array}$ & $\begin{array}{l}P w \\
(m m H g)\end{array}$ & $\begin{array}{l}\text { P. ed. before } \\
\text { PA cath? }\end{array}$ & $\begin{array}{l}\text { Fluid } \\
\text { balance }\end{array}$ & $\begin{array}{l}\text { Did patient } \\
\text { survive? }\end{array}$ \\
\hline Masson $1979^{15}$ & $24 \mathrm{hrs}$ & $41 / 26$ & 22 & Yes & ++ colloid & Yes \\
\hline Duff $1983^{16}$ & $50 \mathrm{~min}$ & 26.6 & 18 & Yes & $+7160 \mathrm{ml}$ & Yes \\
\hline Dolyniuk $1983^{17}$ & 48 hrs & 23 & 14 & Yes & $?$ & Yes \\
\hline Schaerf $1977^{18}$ & 2 hrs & 15 & 10 & No & $+1000 \mathrm{ml}$ & Yes \\
\hline Clark $1985^{10}$ & $70 \mathrm{~min}$ & 29 & 19 & Yes & $?$ & No \\
\hline Quance $1988^{19}$ & 2 hours & $75 / 34$ & 32 & Yes & $?$ & No \\
\hline \multirow[t]{3}{*}{ Shah $1986^{20}$} & AFE & & & No & $?$ & Yes \\
\hline & - Before & $35 / 9$ & 14 & & & \\
\hline & - After & $38 / 16$ & $?$ & & & \\
\hline \multirow[t]{4}{*}{ Clark $1988^{9}(4$ cases $)$} & Within 1-2 hrs & 18 & 16 & $?$ & $?$ & $?$ \\
\hline & & 42 & 31 & & & \\
\hline & & 21 & 16 & & & \\
\hline & & 25 & 14 & & & \\
\hline Girand $1986^{21}$ & $5 \mathrm{hrs}$ & 16 & 12 & Yes & Not excessive & Yes \\
\hline Moore $1982^{22}$ & $20 \mathrm{hrs}$ & 27 & 21 & Yes & $+3000 \mathrm{ml}$ & Yes \\
\hline
\end{tabular}

TABLE IV Animal data with continuous PPA reported after AFE

\begin{tabular}{llllll}
\hline Authors & $\begin{array}{l}\text { Source } \\
\text { of } A F E\end{array}$ & $\begin{array}{l}\text { Recip of } \\
\text { AFE }\end{array}$ & $\begin{array}{l}\text { AFE } \\
\text { vol }\end{array}$ & $\begin{array}{l}\text { Increase in mean PPA (peak) } \\
\text { (time to) }\end{array}$ & $\begin{array}{l}\text { Maximum time to return } \\
\text { to normal mean PPA }\end{array}$ \\
\hline Reeves $1974^{23}$ & Cow & Calf & $100 \mathrm{ml} \cdot \mathrm{kg}^{-1}$ & Icr. $8 \mathrm{mmHg} 2 \mathrm{~min}$ & $10 \mathrm{~min}$ \\
Attwood $1965^{24}$ & Human & Dog & $50 \mathrm{ml}$ & Incr. $9 \mathrm{~mm} \mathrm{Hg} 1 \mathrm{~min}$ & $30 \mathrm{~min}$ \\
Reis $1969^{25}$ & Sheep & Sheep & $150 \mathrm{ml}$ & Incr. $18 \mathrm{mmHg} 1 \mathrm{~min}$ & $30 \mathrm{~min}$ \\
\hline
\end{tabular}

lowered to correct this cause of reduced blood $\mathrm{O}_{2}$ content reaching the tissues.

The hypoxic effect of cardiac or lung shunts may be improved by increasing venous $\mathrm{O}_{2}$, for example by increasing cardiac output. However, increased cardiac output will increase PPA in the now noncompliant pulmonary vascular bed and may not increase venous $\mathrm{O}_{2}$ levels if the heart consumes more $\mathrm{O}_{2}$ to increase cardiac output. ${ }^{27}$ The correct objective is to decrease the amount of shunt by reducing PPA.

\section{Reduced blood pressure}

The increase in PPA causes a reduction in cardiac output and therefore in blood pressure. If the pulmonary vessels are partially blocked or constricted, insufficient blood reaches the left heart and so preload will decrease. With inadequate preload, stroke volume, cardiac output and blood pressure may fall even if the heart keeps beating and at a more rapid rate. If the blockage is severe enough the heart will arrest. This type of cardiac arrest with a rapid heart rate is unusual. The pump cannot produce an adequate cardiac output without sufficient blood returning to the left heart. Since the problem is the obstructed, vasoconstricted pulmonary vessels, it will be difficult, if not impossible, to improve cardiac output until
PPA falls. Drugs may not improve cardiac output and CPR is useless since there is insufficient blood in the left ventricle to pump out. In this setting, the heart working maximally is far more effective than CPR. The outcome will be determined by how long the PPA is increased: if the PPA remains high, neurological damage may occur first and death may result regardless of the treatment applied.

The solution to the problem is to unblock the pulmonary vessels but there is no known way to remove AFE. Isuprel ${ }^{11,28,29}$ has been suggested to decrase PVR but it may also decrease arterial blood pressure. Since stroke volume is low increased heart rate improves cardiac output. This was done with ephedrine but, even then the blood pressure was abnormal. If pulmonary vessel obstruction and vasoconstriction are severe even heart rate increases cannot maintain cardiac output since cardiac output is limited by how much blood can pass through the lungs.

Although epinephrine is more potent than ephedrine it is not certain which is more effective. In this case 25 mg ephedrine were given and the heart rate increased to $147 \cdot \mathrm{min}^{-1}$ at $8: 52$ and to $156 \cdot \mathrm{min}^{1}$ at $8: 57$ (Table I). The maximum effective heart rate is $160 \cdot \mathrm{min}^{-1}$ : at higher rates the heart is beating so rapidly that it has 
no time to fill between beats. Vasopressors may also increase myocardial contractility and myocardial contractility increases when heart rate increases. Both ephedrine and epinephrine increase SVR. If BP is low, an increase in SVR might increase coronary perfusion and decrease perfusion to organs that are temporarily unnecessary (e.g., skin, muscle, gut and kidney). The effect of epinephrine is impeded in acidosis; epinephrine constricts pulmonary vessels and in the presence of hypoxaemia and acidosis epinephrine may result in ventricular fibrillation.

If cardiac output can be improved, hypoxaemia might be reduced and coronary and cerebral perfusion might be increased. The available data are from animal studies and with emboli other than AFE but they provide suggestions that might be useful in the treatment of AFE. Dog experiments with starch microemboli ${ }^{27}$ found that volume infusions were effective in increasing cardiac output but also increased lung water: volume infusions worsened right ventricular dysfunction when PPA was increased. ${ }^{30}$ Nitroprusside was effective ${ }^{27}$ with volume, in increasing cardiac output but could not be used in the face of extreme hypotension. Dobutamine increased cardiac output ${ }^{27}$ by increasing heart rate, but did not increase venous $\mathrm{O}_{2}$ levels because the increased $\mathrm{O}_{2}$ consumption of the heart used up the $\mathrm{O}_{2}$ provided and it increased PPA. Angle et al..$^{31}$ found that norepinephrine increased cardiac output and blood pressure after blood clot emboli in dogs. This was associated with an improvement in right ventricular performance, perhaps from increased coronary perfusion to the right ventricle. No measurements of pulmonary oedema were made. The suggestion that systemic vasoconstriction with neosynephrine is helpful has been made by State et al..$^{32}$ Alpha vasoconstriction may be helpful after AFE as coronary perfusion pressures to a stressed right ventricle may improve and blood flow to organs such as the skin, gut, and kidneys is reduced, but is improved to the brain and heart. The 30-min time course of pulmonary hypertension after AFE found in animals is short enough to suggest that reduced perfusion to gut and kidney by alpha vasoconstriction may not create permanent damage.

The difficulty in treating severe pulmonary hypertension after AFE, results from the effect of maximally distended pulmonary vessels that now behave like rigid pipes. The only way to increase flow through rigid pipes is to increase the driving pressure, PPA, but the high PPA is the major problem in AFE. Even nitroprusside increased PPA when cardiac output increased. ${ }^{27}$ In the most serious cases of AFE probably a combination of increased myocardial contractility, heart rate, volume infusions and increased SVR will all be needed. Epinephrine will provide most of these and alpha vasopressors appear to be beneficial in animal experiments. No matter which therapy is chosen the result will not only depend on the therapy but on the degree of obstruction of the pulmonary vessels created by the emboli and therefore on the PPA.

The cause of the reduced BP (ending in a cardiac arreset) of an amniotic fluid pulmonary embolus is also debated. The cause may be (1) obstruction in the pulmonary vessels preventing blood from getting to the left side of the heart (2) hypoxaemia or chemicals reducing the heart's ability to function, (3) emboli in the coronary circulation creating ischaemic heart muscle, or (4) the same, or other, chemicals that create pulmonary vasoconstriction may also cause myocardial damage. ${ }^{21}$

Diffuse intravascular coagulation (DIC) is very common in documented cases of amniotic fluid embolism. The mechanism may relate to tissue damage caused by the effects of hypoxaemia and a low cardiac output but since DIC is not as common in patients after cardiac arrest from causes other than amniotic fluid embolism the DIC probably results from the chemical changes induced by the amniotic fluid embolus. This patient had DIC.

Brain damage is very common in any patient who survives an amniotic fluid pulmonary embolus in spite of immediate intensive resuscitation. Current data ${ }^{8}$ state that $86 \%$ of patients will die after an amniotic fluid embolus and permanent brain damage is common in the survivors. There are three possible causes of damage to the brain:

1 The AFE may pass through an existing foramen ovale. Once in the left heart they are distributed throughout the body in proportion to blood flow. As the brain receives a higher proportion of the cardiac output it will also receive a higher proportion of the emboli. Also, the first large vessels that come off the aorta pass to the brain. Other organs are protected from emboli by vasoconstriction and they may not be detected.

2 The AFE may go through the lungs themselves. Byrick et al. ${ }^{33}$ showed in dogs, that within two hours fat emboli move out into the lung to obstruct progressively smaller vessels. This reduces PPA and may account for the rapid reduction in PPA after emboli. They also found fat emboli in the brain and kidneys of a size that could pass through the lungs in dogs who did not possess a patent foramen ovale. This suggests that the less viscous material in an AFE is even more likely to pass through the lungs and be responsible for diffuse brain damage.

3 Thirdly, brain damage after AFE may result from the combination of a low $\mathrm{PaO}_{2}$ and low cardiac output which reduce $\mathrm{O}_{2}$ transport to the brain. Normally, if resuscitation is successful within five minutes of cardiac arrest the brain survives because the blood bathing it 
contains $\mathrm{O}_{2}$ which can be used until perfusion with oxygenated blood is resumed. The contraction of hypoxaemia and poor perfusion leads to early brain damage. There is little time for resuscitation, CPR is ineffective and the increased PPA prevents filling of the left ventricle. Until PPA decreases manoeuvres will be ineffective in preventing brain damage.

There are no data concerning brain damage in the few patients who survive an AFE. We analyzed all cases of AFE described since 1977 in which there was a description of the neurological result. $10,14-18,20-22,34,35$ Permanent neurological injury occurred in $8 \%$ if the patient survived and $25 \%$ if the patient died because the neurological damage was so severe.

\section{Subgroups of patients with AFE}

Since the number of emboli are variable in an AFE there will be a spectrum of presentations. There are three categories of patients who suffer AFE. The first two (emboli through the lungs or foramen ovale) should create brain damage and the third problem is pulmonary oedema.

\section{Emboli through the lungs}

It is likely that AFE, like fat emboli, ${ }^{23}$ will pass through the lungs.

\section{Foramen ovale - paradoxical emboli}

Although the incidence of foramen ovale has been quoted as $35 \%$ ( 0.6 to $1 \mathrm{~cm}$ foramen ovale in $6 \%$ and 0.2 to $0.5 \mathrm{~cm}$ foramen ovale in $29 \%$ of unselected autopsies) by Thomson and $25 \%$ by Hagan et al. ${ }^{37}$ clinical studies consistently suggested a lower incidence, but the difference has been explained by Konstadt et al. ${ }^{38}$ who found an overall incidence of foramen ovale of $26 \%$ in patients without atrial septal defects, in contrast to 6 and 18\% reported by others. ${ }^{39-42}$ The higher figure agreed with the autopsy data of Hagen et al. ${ }^{37}$ and Thompson et al. ${ }^{36}$ They found that when right-sided heart pressures were increased the incidence of foramen ovale increased from $10 \%$ to $22 \%$ and after adding Doppler recordings it increased further to $26 \%$. The AFE are small (microscopic) and so can pass through a hole as small as $0.2 \mathrm{~cm}$.

Harvey et al ${ }^{43}$ studied 286 patients after a stroke who were thought not to have a foramen ovale. In eleven $<50 \mathrm{yr}$, a CAT scan showed no evidence of haemorrhagic stroke, heart valve defects, or clots inside their hearts, ECG was unchanged and there was no evidence of atherosclerotic cerebrovascular disease, and chest $x$-rays and cerebral physical findings were normal. Eight of the eleven patients were shown to have a foramen ovale. The authors conclude "we found an unexpectedly high association between interatrial defects and stroke in eleven young patients, raising the possibility that paradoxical cerebral embolization is commoner than is usually believed."

Fat emboli may pass through lung capillaries to reach the systemic circulation. Thus, it is likely that AFE which is less viscous than fat will also pass through the lungs which is corroberated by the reports of AFE in the brain, heart, liver, and kidney. In some studies, ${ }^{24,44-46}$ a foramen ovale was not looked for. There are only two ways for emboli to reach the systemic circulation, either through the lungs or through a foramen ovale.

\section{Pulmonary oedema}

Clark ${ }^{47}$ suggested that after the initial AFE problems due to PPA (phase one) a secondary event, left ventricular failure, may lead to pulmonary oedema (phase two). However, in most of the cases reported ${ }^{10,15-17,19,21,22}$ pulmonary oedema was present before the catheter was inserted (Table III). In the remaining two reports ${ }^{18,20}$ there were other reasons for inserting the catheter and pulmonary oedema did not occur.

The reported incidence of pulmonary oedema varies from $24 \%$ to $70 \% .{ }^{46}$ However, pulmonary oedema is difficult to detect even when based on lung weight at post mortem. Until there is a $60 \%$ increase in lung water we have difficulty seeing it on chest $x$-ray, or hearing it with a stethoscope, and blood gases and oxygenation will be normal. ${ }^{48}$ A $60 \%$ increase in lung weight from $600 \mathrm{~g}$ takes us to $1000 \mathrm{~g}$. Therefore Peterson ${ }^{46}$ found only three cases of 40 with sufficient pulmonary oedema that it could have been detected clinically. Another $48 \%$ of patients had smaller (clinically undetectable) increases in lung water in the interstitial phase.

Peterson ${ }^{46}$ and then Clark $^{10}$ suggest that large increases in pulmonary oedema that can be detected clinically are unusual.

If pulmonary microvascular pressure (Pmv)

$\mathrm{Pmv}=\mathrm{Pla}+0.4(\mathrm{PPA}-\mathrm{Pla})^{49}$

is increased pulmonary oedema will, over time, increase..$^{50}$ Pulmonary oedema will not accumulate for several hours because it must overcome several safety factors built into the lungs to keep them dry. First, protein in blood and the surrounding tissues holds fluid inside vessels, second, the lung can carry away, through lymphatics, a 30-fold increase in the production of pulmonary oedema. But if Pmv stays high enough, long enough, pulmonary oedema will eventually result. Thus, delayed pulmonary oedema after AFE will show up following (a) the infusion of large amounts of fluid to increase Pmv or (b) left ventricular dysfunction.

In those reports of AFE in which the details of fluid administration, PA catheter information, and the presence 
of pulmonary oedema are complete (Table III), three of four patients had excessive fluid administered and high Pmv. ${ }^{15,16,22}$ In a fourth patient ${ }^{21}$ treatment for pulmonary oedema with furosemide was given before the PA catheter was inserted. None of the mechanisms that create pulmonary oedema can account for the initial reduced $\mathrm{PaO}_{2}$ after AFE since it occurs too rapidly. Only later can pulmonary oedema play a role in reducing $\mathrm{PaO}_{2}$.

Pulmonary oedema may occur after AFE for the same reasons as it occurs in other situations, i.e., by an increase in Pmv. Whether pulmonary oedema occurs will depend on how much fluid is infused and the heart damage done by the AFE. Most, $76 \%$, of 272 patients did not develop pulmonary oedema after AFE.

\section{Relationship to patient}

The sudden onset of dyspnoea, cyanosis, hypotension, convulsions and DIC are typical of AFE (or air emboli) in a pregnant patient. In 1987 neither pulse oximetry nor end-tidal $\mathrm{CO}_{2}$ were available to aid in the diagnosis. The haemodynamic profile (Table I) indicates that the patient had an AFE before 08:41. If a convulsion occurred, emboli may have passed through a foramen ovale. The administration of $\mathrm{O}_{2}$, tracheal intubation and ventilation were not effective in correcting the shunt. By 08:52 the combination of reduced PPA, fluid and ephedrine resulted in an improved BP at near maximum heart rates. At 08:57 a second AFE obstructed more pulmonary vasculature. The obstruction to blood flow and the lack of further cardiac reserves resulted in undetectable BP. The improvement in BP at 09:08 (Table I) may have been due to a reduction in PPA.

After oxygenation and blood pressure returned to normal the heart rate remained elevated because an $\mathrm{O}_{2}$ debt has to be paid back to tissues. The Swan-Ganz catheter inserted one hour later found normal values which was compatible with both an AFE and other patient data. ${ }^{21}$ The chest $x$-rays and breath sounds were normal. Pulmonary oedema was not seen but it is possible that some pulmonary oedema ( $<60 \%$ increase) was present but this amount of oedema would not be heard by stethoscope or seen on chest $x$-ray and would not modify blood gases. Whether clinicians should accept the risk of pulmonary oedema by infusing large fluid volume loads in an attempt to increase venous return to the left heart after AFE is debatable. On balance, aggressive fluid volume infusions and high-dose inotropes (epinephrine, norepinephrine, isuprel, dobutamine and/or dopamine) in an attempt to improve cardiac output rapidly at the point of highest initial PPA and lowest cardiac output might have an opportunity for success. Of these, norepinephrine has provided benefits in animal experiments. The pulmonary oedema that might result could then be dealt with later (once the AFE obstruction of the pulmonary vascular bed has abated).

The only diagnostic tool missing is a sample of pulmonary artery blood for "squames." But, the value of this test has been questioned since "squames" occur in the pulmonary venous blood of pregnant patients without symptoms of AFE..$^{51,52}$ Other tests, ECG, lung scan, chest $x$-ray and pulmonary angiograms are not helpful in most cases because even small amounts of emboli can create a large amount of damage.

We should recognize ${ }^{53}$ that the patient outcome may not be changed by therapy regardless of how aggressive it may be. Rather outcome will be determined by the number of emboli reaching the pulmonary, brain or coronary vascular beds. Nevertheless, we must be prepared to deal with this sudden, unheralded, and potentially catastrophic event in any pregnant patient.

\section{References}

1 Carroll GC. Blood pressure monitoring. Crit Care Clin 1988; 4: 411-20.

2 Handler JS, Bromage PR. Venous air embolism during Cesarean delivery. Reg Anesth 1990; 15: 170-3.

3 Robinson DA, Albin MS. Venous air embolism and Cesarean sections (Corresp). Anesthesiology 1987; 66: 93-4.

4 Malinow AM, Naulty JS, Hunt CO, Datta S. Ostheimer $G W$. Precordial ultrasonic monitoring during Cesarean delivery. Anesthesiology 1987; 66: 816-9.

5 Fong J, Gadalla F. Precordial Doppler diagnosis of haemodynamically compromised air embolism during Caesarean section. Can J Anaesth 1990; 37: 262-4.

6 Karuparthy VR, Downing JW, Husain FJ, et al. Incidence of venous air embolism during Cesarean section is unchanged by the use of a 5 to $10^{\circ}$ head-up tilt. Anesth Analg 1989; 69: 620-3.

7 Jackson KE, Rauck $R L$. Suspected venous air embolism during epidural anesthesia. Anesthesiology 1991; 74: 190-1.

8 Morgan M. Amniotic fluid embolism. Anaesthesia 1979; 34: 20-32.

9 Clark SL, Cotton DB, Gonik B, Greenspoon J, Phelan P. Central hemodynamic alterations in amniotic fluid embolism. Am J Obstet Gynecol 1988; 158: 1124-6.

10 Clark SL, Montz FJ, Phelan JP. Hemodynamic alterations associated with amniotic fluid embolism: a reappraisal. Am J Obstet Gynecol 1985; 151: 617-1.

11 Halmagyi DFJ, Starzecki B, Shearman RP. Experimental amniotic fluid embolism: mechanism and treatment. Am J Obstet Gynecol 1962; 84: 251-6.

12 Steiner PE, Lushbaugh CC. Maternal pulmonary embolism by amniotic fluid. JAMA 1941; 117: 1245-80.

13 Azegami M, Mori N. Amniotic fluid embolism and leukotrienes. Am J Obstet Gynecol 1986; 155: 1119-24. 
14 Mainprize TC, Maltby JR. Amniotic fluid embolism: a report of four probable cases. Can J Anaesth 1986; 33: 382-7.

15 Masson RG, Ruggeiri J, Siddiqui MM. Amniotic fluid embolism: definitive diagnosis in a survivor. Am Rev Resp Dis 1979; 120: 187-92.

16 Duff $P$, Engelsjerd B, Zingery LW, Huff RW, Monteil MM. Hemodynamic observations in a patient with intrapartum amniotic fluid embolism. Am J Obstet Gynecol 1983; 146: $112-5$.

17 Dolyniuk M, Orfei E, Vania H, Karlman R, Tomich P. Rapid diagnosis of amniotic fluid embolism. Obstet Gynecol 1983; 61: 28S-34S.

18 Schaerf RHM, de Campo T, Civetta JM. Hemodynamic alterations and rapid diagnosis in a case of amniotic fluid embolus. Anesthesiology 1977; 46: 155-7.

19 Quance D. Amniotic fluid embolism: detection by pulse oximetry. Anesthesiology 1988; 68: 951-2.

20 Shah K, Karlman R, Heller J. Ventricular tachycardia and hypotension with amniotic fluid embolism during Cesarean section. Anesth Analg 1986; 65: 533-5.

21 Girard P, Mal H, Laine JF, Petitpretz P, Rain B, Duroux $P$. Left heart failure in amniotic fluid embolism. Anesthesiology 1986; 64: 262-5.

22 Moore $P G$, James $O F$, Saltos $N$. Severe amniotic fluid embolism: case report with haemodynamic findings. Anaesth Intensive Care 1982; 10: 40-4.

23 Reeves JT, Daoud FS, Estridge M, Stone WH, McGary D. Pulmonary pressor effects of small amounts of bovine amniotic fluid. Respir Physiol 1974; 20: 231-7.

24 Attwood HD, Downing SE. Experimental amniotic fluid and meconium embolism. Surg Gynecol Obstet 1965; 120: 255-63.

25 Reis RL, Pierce WS, Behrendt DM. Hemodynamic effects of amniotic fluid embolism. Surg Gynecol Obstet 1969; 129: 45-8.

26 Fisher J, Noble WH, Kay JC. Hypoxemia after pulmonary embolism: a dog model of altering regional perfusion. Anesthesiology 1981; 54: 204-9.

27 Noble WH, Kay JC. The effects of dobutamine, nitroprusside, or volume expansion on cardiac output after CPPV. Can Anaesth Soc 1986; 33: 48-56.

28 Ducas J, Duval D, Dasilva H, Boiteau P, Prewitt RM. Treatment of canine pulmonary hypertension: effects of norepinephrine and isoproterenol on pulmonary vascular pressure-flow characteristics. Circulation 1987; 75: 235-42.

29 Molloy DW, Lee KY, Jones D, Penner B, Prewitt RM. Effects of noradrenaline and isoproterenol on cardiopulmonary function in a canine model of acute pulmonary hypertension. Chest 1985; 88: 432-5.

30 Ghgnone $M$, Girling L, Prewitt RM. Volume expansion versus norepinephrine in treatment of a low cardiac output complicating an acute increase in right ventricular afterload in dogs. Anesthesiology 1984; 60: 132-5.

31 Angle MR, Molloy DW, Penner B, Jones D, Prewitt RM. The cardiopulmonary and renal hemodynamic effects of norepinephrine in canine pulmonary embolism. Chest 1989; 95: 1333-7.

32 State D, Salisbury PF. The experimental production of the pulmonary embolism syndrome and the effects of variations of systemic arterial pressure on its course. Surg Gynecol Obstet 1956; 103: 202-8.

33 Byrick RJ, Mullen MD, Wigglesworth DF. Pulmonary and systemic fat embolism after cemented arthroplasty. Can J Anaesth 1993; 40: A18.

34 Ricou B, Reper P, Suter PM. Rapid diagnosis of amniotic fluid embolism causing severe pulmonary failure. Intensive Care Med 1989; 15: 129-31.

35 Ratten GT. Amniotic fluid embolism - 2 case reports and a review of maternal deaths from this cause in Australia Aust NZ J Obstet Gynaecol 1988; 28: 33-5.

36 Thompson T, Evans $W$. Paradoxical embolism. QJ Med 1930; 23: 135-50.

37 Hagen PT, Scholz DG, Edwards WD. Incidence and size of patent foramen ovale during the first 10 decades of life: an autopsy study of 935 normal hearts. Mayo Clin Proc 1984; 59: 17-20.

38 Konstadt SN, Louie EK, Black S, Rao TLK, Scanlon P. Intraoperative detection of patent foramen ovale by transesophageal echocardiography. Anesthesiology 1991; 74: 212-6.

39 Lechat P, Mas $J L$, Lascault $G$, et al. Prevalence of patent foramen ovale in patients with stroke. N Engl J Med 1988; 318: 1148-52.

40 Black S, Muzzi DA, Nishimura RA, Cucchiara RF. Preoperative and intraoperative echocardiography to detect right-left shunt in patients undergoing neurosurgical procedures in the sitting position. Anesthesiology 1990; 72: 436-8.

41 Lynch JJ, Schuchard GHG, Gross CM, Wann LS. Prevalance of right-to-left atrial shunting in the healthy population: detection by Valsalva maneuver contrast echocardiography. Am J Cardiol 1984; 53: 1478-80.

42 Guggiari M, Lechat PL, Garen-Colonne C, Fusciardi J, Viars $P$. Early detection of patent foramen ovale by twodimensional contrast echocardiography for prevention of paradoxical air embolism during sitting position. Anesth Analg 1988; 67: 192-4.

43 Harvey JR, Teague SM, Anderson JL, Voyles WF, Thadani $U$. Clinically silent atrial septal defects with evidence for cerebral embolization. Ann Intern Med 1986; 105: 695-7.

44 Ishiyama I, Mukaida M, Komuro E, Keil W. Analysis of a case of generalized amniotic fluid embolism by demonstrating the fetal isoantigen (A blood type) in maternal 
tissues of B blood type using immunoperoxidase staining. Am J Clin Pathol 1986; 85: 239-41.

45 Liban E, Raz $S$. A clinicopathological study of fourteen cases of amniotic fluid embolism. Am J Clin Pathol 1969; 51: 477-86.

46 Peterson EP, Taylor HB. Amniotic fluid embolism: an analysis of 40 cases. Obstet Gynecol 1970; 35: 787-93.

47 Clark SL. New concepts of amniotic fluid embolism: a review. Obstet Gynecol Surv 1990; 45: 360-8.

48 Noble $W H$, Kovas $K$, Kay JC. Fine structural changes in haemodynamic pulmonary oedema. Can Anaesth Soc J 1974; 21 : 275-84.

49 Garr KA, Taylor AE, Owens $L J$, Guyton AC. Pulmonary capillary pressure and filtration coefficient in the isolated perfused lung. Am J Physiol 1967; 213: 910-5.

50 Noble WH. Pulmonary oedema: a review. Can Anaesth Soc J 1980; 27: 286-301.

51 Lee W, Ginsburg KA, Cotton DB, Kaufman RH. Squamous and trophoblastic cells in the maternal pulmonary circulation identified by invasive hemodynamic monitoring during the peripartum period. Am J Obstet Gynecol 1986; 155: 999-1003.

52 Clark SL, Pavlova Z, Greenspoon J, Horenstein J, Phelan $J P$. Squamous cells in the maternal pulmonary circulation. Am J Obstet Gynecol 1986; 154: 104-6.

53 St-Amand, J. Medioclegal nightmare: a tragic case, a needless trial. CMAJ 1993; 148: 806-9. 